\title{
The protective effects of grape seed oil on induced osteoarthritis of the knee in male rat models
}

\author{
Nader Tanideh ${ }^{1,2}$, Soheil Ashkani-Esfahani ${ }^{3,4^{*}}$ (D), Farid Sadeghi ${ }^{5}$, Omid Koohi-Hosseinabadi ${ }^{1,6}$, Cambyz Irajie $^{7 *}$,
} Aida Iraji ${ }^{6}$, Bart Lubberts ${ }^{3,4}$ and Soleiman Mohammadi Samani ${ }^{8}$

\begin{abstract}
Background: Osteoarthritis $(\mathrm{OA})$, though being treated via various methods and medicines, is still a major healthcare concern mostly due to the increase in diagnosis of these age-related diseases. The present study aimed at investigating the effects of oral and intra articular injection of grape seed oil on OA in male rat models.

Methods and materials: Seventy male rats were selected and their anterior cruciate ligament was cut to induce OA. They were divided into 7 groups $(n=10)$ : C1, no treatment; $C 2$, receiving $300 \mathrm{mg} /$ day of Piascledine per os (PO); C3, 1 mg sodium hyaluronate intra-articularly in days 1, 7, 14; C4, 1 mg methyl-prednisolone acetate intraarticularly; E1, avocado and grape seed oil combination (2:1, 300 mg/day) PO; E2, 500 mg/day of grape seed oil PO; E3, $200 \mathrm{mg} /$ day grape seed oil intra-articularly. After 10 weeks, the rats were anesthetized and evaluated radiologically and histopathologically. $P$ value $\leq 0.05$ was considered as statistically significant.

Results: All the groups made significant differences with $C 1$ regarding all inspected radiological criteria $(P \leq 0.05)$. E1 and E3 showed significantly better effects on medial femoral condyle, medial tibial condyle, joint space width, total osteophyte, and OA scores $(P \leq 0.04)$.

Joint surface, matrix, cell distribution, cell population viability, calcification, and subchondral bone in treatment groups had significantly better scores versus $C 1(P \leq 0.04)$. E1 and E3 had significantly superior results regarding joint surface, cell viability, and calcification $(P \leq 0.04)$.

Conclusions: Grape seed oil has protective effects, both in injectable form and PO in combination with avocado, on $O A$ in rats. Further clinical trials are necessary.
\end{abstract}

Keywords: Osteoarthritis, Grape seed oil, Anti-inflammation, Anti-oxidant

\footnotetext{
* Correspondence: soashkani@gmail.com; irajie@sums.ac.ir;

Kmtx2100@yahoo.com

${ }^{3}$ Department of Orthopaedic Surgery, Massachusetts General Hospital, Harvard Medical School, Boston, MA, USA

${ }^{7}$ Department of Medical Biotechnology, School of Advanced Medical Sciences and Technologies, Shiraz University of Medical Sciences, Shiraz, Iran Full list of author information is available at the end of the article
}

C C The Author(s). 2020 Open Access This article is licensed under a Creative Commons Attribution 4.0 International License, which permits use, sharing, adaptation, distribution and reproduction in any medium or format, as long as you give appropriate credit to the original author(s) and the source, provide a link to the Creative Commons licence, and indicate if changes were made. The images or other third party material in this article are included in the article's Creative Commons licence, unless indicated otherwise in a credit line to the material. If material is not included in the article's Creative Commons licence and your intended use is not permitted by statutory regulation or exceeds the permitted use, you will need to obtain permission directly from the copyright holder. To view a copy of this licence, visit http://creativecommons.org/licenses/by/4.0/ The Creative Commons Public Domain Dedication waiver (http://creativecommons.org/publicdomain/zero/1.0/) applies to the data made available in this article, unless otherwise stated in a credit line to the data. 


\section{Introduction}

Knee osteoarthritis (OA) is a degenerative joint disease and a dominant cause of pain and disability; OA is described as a slow development disease that is mostly diagnosable in its terminal phase [1]. About $10 \%$ of men and $13 \%$ of women at the age of over 60 years present with symptoms of knee OA. These symptoms mostly include morning stiffness, joint pain, and joint deformities that affect the quality of life and functional outcomes [2, 3]. To date, there is no definite treatment for this chronic disease and most of the therapeutic methods are focused on symptom management and in severe cases, joint replacement is considered [4,5]. Previous experiments concluded that the prevention of anti-inflammatory and pro-inflammatory pathways as well as reducing oxidative stress may lead to controlling the development of the OA $[6,7]$. Numerous studies found that some herbal medicines due to their immune modulating, anti-inflammatory, and antioxidative effects can prevent OA in experimental models. These medicines are increasingly becoming popular for the treatment of OA symptoms, particularly in experiments and research $[8,9]$. In populations with traditional beliefsi.e., some areas in the middle east countries such as Iran, the will for using traditional and natural medicines gave us the idea to work on some of these medicines that are believed to be effective among them in order to introduce effective and cost-benefit treatments for those suffering from $O A$ and its symptoms.

Grape seed is well known for its variety of antioxidative derivatives such as oligomeric proanthocyanidins and catechins, as well as anti-inflammatory potentials, is one of the most popular remedies for the treatment of OA $[10,11]$. Literature reported that the efficacy of grape seed extract administered orally on OA in rats led to the prevention of loss of chondrocyte cells and proteoglycan, formation of osteophytes, reducing reactive oxygen species, and inflammation mediators such as MMP13, nitrotyrosine, and IL-1 $\beta$, in experimental models $[8,12]$. The purpose of the present study was to determine the effects of grape seed oil treatment for the prevention of knee OA by evaluating radiological and histopathological outcomes.

\section{Materials and methods}

\section{Grape seed oil material and extraction}

In this study, different attempts were made to prepare emulsions of grape seed oil (Pietro Coricelli ${ }^{\mathrm{Tx}}$, Italy) with various combinations of the constituents. Out of these attempts, the following three series of emulsions were prepared with different hydrophilic-lipophilic balance (HLB) (HLB: 9, 10, 11, 12). Emulsification was performed using the following procedures. Initially, grape seed oil was transferred to the beaker and heated at $20^{\circ} \mathrm{C}$, then water, as the solvent, was added. Subsequently, the emulsifier was added under intense agitation at $500 \mathrm{rpm}$ for $5 \mathrm{~min}$. Then, in the case of groups I and II, as described below, the mixture was mixed for an extra $25 \mathrm{~min}$; however, group III was completely digested by applying $10 \mathrm{~min}$ ultrasonic homogenizer. Finally, the mixture was sterilized by autoclave $\left(121^{\circ} \mathrm{C}\right.$ for $15 \mathrm{~min}$ ) and the emulsion was packaged under a laminar hood with aseptic conditions.

I) Tween 80 (as a nonionic emulsifier in the aqueous phase)/Span 20 (as an emulsifier of lipid-containing compounds)/stirring:

A: 25 g grape seed oil +23 g water $15 \%+0.9375$ Span $20+0.0625$ of Tween 80

B: 25 g grape seed oil + 23 g water $15 \%+0.78$ Span 20 +0.22 of Tween 80

C: 25 g grape seed oil +23 g water $15 \%+0.625$ Span $20+0.375$ of Tween 80

D: 25 g grape seed oil + 23 g water $15 \%+0.42$ Span 20 +0.53 of Tween 80

\section{II) Tween $80 /$ Span 60/stirring}

E: 25 g grape seed oil +22.5 g water $15 \%+1.455$ Span $60+1.04$ of Tween 80

F: 25 g grape seed oil +22.5 g water $15 \%+1.215$ Span $60+1.285$ of Tween 80

G: 25 g grape seed oil +22.5 g water $15 \%+0.975$ Span $60+1.525$ of Tween 80

$\mathrm{H}: 25 \mathrm{~g}$ grape seed oil $+22.5 \mathrm{~g}$ water $15 \%+0.72$ Span $60+1.77$ of Tween 80

III) Tween 80/Span 60/homogenizer/5\% emulsifier

I: 25 g grape seed oil +22.5 g water $15 \%+1.455$ Span $60+1.04$ of Tween 80

J: 25 g grape seed oil +22.5 g water $15 \%+1.215$ Span $60+1.285$ of Tween 80

K: 25 g grape seed oil +22.5 g water $15 \%+0.975$ Span $60+1.525$ of Tween 80

L: 25 g grape seed oil +22.5 g water $15 \%+0.72$ Span $60+1.77$ of Tween 80

IV) Tween 80/Span 60/homogenizer/2.5\% emulsifier

M: $25 \mathrm{~g}$ grape seed oil $+23.75 \mathrm{~g}$ water $15 \%+0.7275$ Span $60+0.52$ of Tween 80

$\mathrm{N}: 25 \mathrm{~g}$ grape seed oil $+23.75 \mathrm{~g}$ water $15 \%+0.6075$ Span $60+0.6425$ of Tween 80

O: 25 g grape seed oil +23.75 g water $15 \%+0.4875$ Span $60+0.7625$ of Tween 80 


\section{Assessment of stability, standardization, and phytochemical analysis of grape seed oils}

Group III with the ratio of 40:60\% with an emulsifier (5\%) and group IV with the ratio of $40: 60 \%$ with $2.5 \%$ emulsifier was evaluated for the monitoring of stability in a room $\left(24{ }^{\circ} \mathrm{C} \pm 1\right)$ and fridge $\left(2{ }^{\circ} \mathrm{C} \pm 1\right)$ temperatures.

The 1, 1-diphenyl-2-picrylhydrazyl radical (DPPH) is a stable radical with a maximum absorbance at $517 \mathrm{~nm}$ that can readily undergo reduction by an antioxidant. The scavenging effect on DPPH radical was determined by the method reported earlier with minor modifications [13]. Different concentrations of grape seed oil in methanol $(20 \mu \mathrm{l})$ were mixed with $270 \mu \mathrm{l}$ of $0.004 \%$ methanolic solution of DPPH. The mixture was shaken vigorously and left to stand for $30 \mathrm{~min}$ in dark at $30{ }^{\circ} \mathrm{C}$, and the absorbance was then measured at $517 \mathrm{~nm}$ with a FLUostar OPTIMA spectrophotometer (BMG Labtech, Germany).

\section{Avocado extract preparation}

Avocado fruits were obtained from a local market. Two hundred and fifty gram avocado slices were blended and macerated in $500 \mathrm{ml}$ of alcohol (70\% ethanol) at room temperature. The product was then filtered and the alcoholic extract was collected (the first portion). Subsequently, another $500 \mathrm{ml}$ of ethanol was added to the residues, boiled for about $2 \mathrm{~h}$ under reflux condenser in a water bath, and then filtered. The filtrate was collected and added to the first portion. Together, these two portions formed the plant residue. Afterward, $500 \mathrm{ml}$ of distilled water was added to the plant residue and left at room temperature for 2 days, and then filtered and added to the previous crude extract. Another volume of water was added to the residue, boiled for about $2 \mathrm{~h}$ under reflux condenser and filtered. Both products were gathered to form the hydro-alcoholic crude extract. The solvents were evaporated under vacuum by rotary evaporator. The extract was obtained and stored in a freezer until use.

\section{Induction of knee osteoarthritis and grouping}

Seventy Sprague-Dawley male rats were used in this study, obtained from the animal center of Shiraz University of Medical Sciences. Animals were kept at $23 \pm 2{ }^{\circ} \mathrm{C}$ and a $12 \mathrm{~h}$ light: $12 \mathrm{~h}$ dark cycle, 1 week before the experiment. On day 1 of the study, OA was induced based on a previously reported method through left anterior cruciate ligament transection under general anesthesia induced by intraperitoneal injection of a mixture of acepromazine and ketamine $(1.25 \mathrm{mg} / \mathrm{kg}$ and $38 \mathrm{mg} / \mathrm{kg}$, respectively) [14]. For preventing infection, tetracycline ointment was used after closing the surgical site.

Post-operatively, all 70 rats were randomly assigned into seven groups $(n=10)$ : Group $C 1$, negative control group with $\mathrm{OA}$ without any treatment; $\mathrm{C} 2$, positive control group receiving $300 \mathrm{mg} /$ day of Piascledine dissolved in 1-2 cc distilled water (Expanscience Laboratories, France) per os (PO) daily from day 1 for 10 weeks; C3, second positive controls receiving $1 \mathrm{mg}$ of sodium hyaluronate (Hyalgan ${ }^{\oplus}$, Fidia Pharmaceutical, Padua, Italy) intra-articularly in the 1st, 7th, and 14th day; C4, positive control group receiving $1 \mathrm{mg}$ methyl prednisolone acetate (Aburaihan Co, Tehran, Iran) intra-articularly in day 1 , then in days 7 and 14; E1, the first experimental group receiving a combination of avocado and grape seed oil emulsion with a ratio of 2:1 (300 mg/day; dissolved in 1-2 cc distilled water) PO daily from day 1 for 10 weeks; E2, $500 \mathrm{mg}$ /day of grape seed oil emulsion PO daily from day 1 for 10 weeks; E3 group treated with $200 \mathrm{mg} /$ day grape seed oil injected intra-articularly in days 1,7 , and 14 . All animals were controlled during 10 weeks of the study. The dosages of the medicines were chosen according to previously conducted pilot experiments and published papers showing the best efficacy with the lowest amount of the agent.

Ethical guidelines for animal studies were respected throughout the experiment period and the protocol was approved by the Ethics Committee of Shiraz University of Medical Sciences.

\section{Radiological and pathological examinations}

Knee joint X-ray images were taken from anteroposterior and lateral aspects of the left knee. All radiographs were performed by the same operator and equipment and by using a standard protocol. OA was assessed by using a grading system based on the International Cartilage Repair Society (ICRS, Table 1) [15]. Scoring subjects were based on radiological features such as narrowing of the joint space, presence of osteophytes, sclerosis of subchondral bone, and deformity of the bone ends included 0 (none), 1 (doubtful), 2 (minimal), 3 (moderate), and 4 (severe). Osteophytes in the medial condyle of the tibia, femur, medial fabella, and total knee joint, joint space width, and total OA score, were investigated. Radiographs were graded by a blinded radiologist.

For pathological evaluation, the joint surfaces were grossly examined after sacrificing the rats. Distal femora were removed and fixed in $10 \%$ buffered formaldehyde. All pieces were embedded in paraffin. Serial sagittal sections were prepared and stained with hematoxylin and eosin (for cellular architecture), toluidine blue, and safranin $\mathrm{O}$ (for proteoglycan contents of the matrix). A blinded pathologist performed the evaluation by using a modified histological grading method provided [16]. A scoring system was based on the following repair indices: surface, matrix, cell distribution, cell population viability, subchondral bone, and cartilage mineralization. More severe damage is indicated with a lower score. All morphometric parameters were recorded with a digital camera system (Olympus Optical, Tokyo, Japan). 
Table 1 Grading system of radiological assessment

\begin{tabular}{|c|c|c|c|c|c|}
\hline \multicolumn{2}{|c|}{ Radiographic OA feature of the medial compartment } & \multirow{2}{*}{$\begin{array}{l}\text { Grade } 0 \\
\text { Normal }\end{array}$} & \multirow{2}{*}{$\begin{array}{l}\text { Grade } 1 \\
\text { Reduced }\end{array}$} & \multirow{2}{*}{$\begin{array}{l}\text { Grade } \mathbf{2} \\
\text { Absent }\end{array}$} & \multirow{2}{*}{$\frac{\text { Grade }}{\text { NA }}$} \\
\hline Joint space $n$ & & & & & \\
\hline \multirow[t]{3}{*}{ Osteophyte } & Medial tibial condyle & Absent & Small & Moderate & Severe \\
\hline & Medial femoral condyle & Absent & Small & Moderate & Severe \\
\hline & Medial fabella & Absent & Present & & NA \\
\hline \multicolumn{2}{|c|}{ Total osteophytes } & & & $0-7$ & \\
\hline \multicolumn{2}{|c|}{ Global OA score } & & & $0-9$ & \\
\hline
\end{tabular}

\section{Statistical analysis}

Gathered data were analyzed by the GraphPad software version 6.0 (San Diego, California). For histopathological and radiological evaluation, non-parametric KruskalWallis and Mann-Whitney $U$ tests were used through the SPSS software version 21.0 (IBM ${ }^{\mathrm{TM}}$, USA). A $P$ value $\leq 0.05$ was considered as statistically significant.

\section{Results}

\section{Grape seed oils emulsification outcome}

Regarding the composition of grape seed oil, in group I, samples A-D, each of the emulsions could not remain constant and two phases were produced. In the second experiment (group II, samples E-H), the Span 60 was used instead of Span 20. After 1 day, the emulsions turned into two phases. In the third experiment (group III, sample I-L), the homogenizer apparatus was used for mixing the lipid and aqueous layer. Interestingly, after 10 days, the emulsion did not turn into two phases. Conclusively, group III was chosen for further evaluations. Another critical factor that should be considered was sterilization. As a result, I-L was autoclaved at $121^{\circ} \mathrm{C}$ for $15 \mathrm{~min}$. The $\mathrm{K}$ and $\mathrm{L}$ samples became two phasic during sterilization and were removed. Finally, G and $\mathrm{K}$ with HLB:10 and ratio of 40:60\% were chosen.

\section{Stability and phytochemical analyses outcomes}

Studying the stability of the emulsion included droplet size determinations and viscosity measurements for a period of 1 day to 3 months in room and fridge temperatures. None of the emulsions of $5 \%$ with HLB = 10 exhibited creaming or phase separation during the abovementioned time period. Finally, samples containing 5\% emulsifier with a ratio of $40: 60 \%$ (lipid: aqueous) were selected in order to have more stability for biological evaluations.

The DPPH assay constitutes a quick and low-cost method that has frequently been used for evaluation of the anti-oxidative potential of various natural products. In the presence of antioxidant agents, the odd electron of $\mathrm{DPPH}$ becomes paired, resulting in the absorption loss. The absorbance change produced by this reaction is assessed to evaluate the antioxidant potential of the test sample. The results revealed that the IC50 scavenging effect of the avocado extract was $0.66 \pm 0.1 \mathrm{mg} / \mathrm{ml}$.

\section{Radiological findings}

Our radiological findings, as shown in Fig. 1, depicted that all of the groups made significant differences with the untreated group $C 1(P \leq 0.05)$ regarding all inspected criteria in this study. Considering the findings of OA in the medial femoral condyle, joint space width, and total score for OA, groups E1 and E3 showed the lowest scores which significantly differed with the other groups $(P \leq 0.04)$. Scores of medial tibial condyle osteophytes were considerably lower in E1, E3, and C4 groups compared to the others $(P \leq$ 0.03), also, E1 and C3 groups depicted noticeably better results in medial fabella osteophytes $(P \leq 0.05)$. Regarding medial fabella osteophytes, total osteophyte, and total OA scores E1 group presented even better results than E3 $(P \leq$ 0.05; Fig. 1).

\section{Histopathological finding}

Pathological evaluation of joint surface, matrix, cell distribution, cell population viability, cartilage calcification, and subchondral bone showed that all treatment receiving groups had significantly better scores compared to C1 showing preventive effects of the treatments in rats with induced OA ( $P \leq 0.04$; Fig. 2). Groups E1 and E3 had significantly better results regarding joint surface, cell population viability, and cartilage calcification scores $(P \leq 0.04)$; E1 had considerably better results in regard to subchondral bone score compared to other PO treatments, and E3 showed noticeably lower score regarding cell distribution compared to other intra-articular treatments $(P \leq 0.05$; Fig. 2$)$.

Evaluation of stained tissue sections of the $\mathrm{C} 1$ group presented irregular surface, fibrosis of the cartilage, and disrupted cell distribution with inflammation in the knee articular surface as well as mineralization of cartilage tissue (Fig. 3).

\section{Discussion}

OA treatment includes medicinal therapy, nonmedicinal therapy, and surgical procedures which are mostly focused on symptom therapies, pain reduction, and improving function overall [17, 18]. Historically, many natural remedies have been introduced as alternative treatments for OA. For instance, plants containing polyphenol components such as cocoa, grape, and pine bark, that through anti-inflammatory, immune 

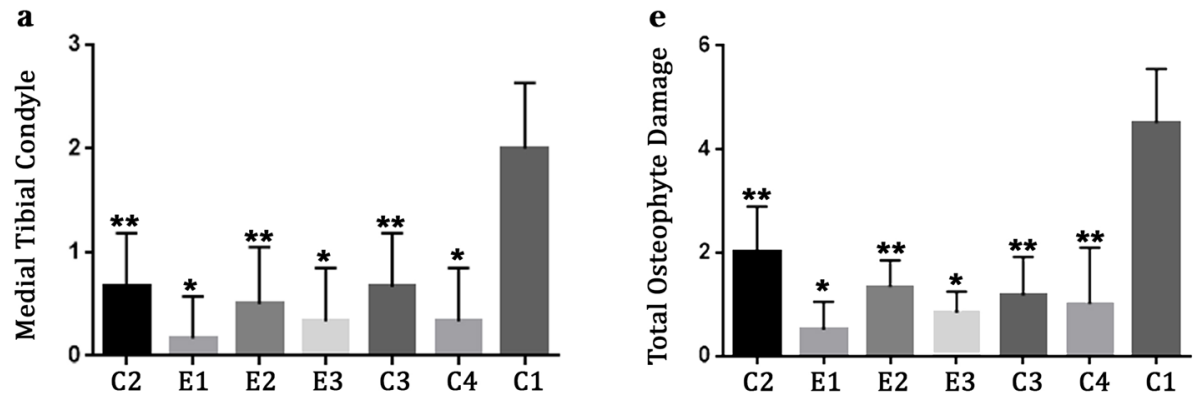

\section{b}

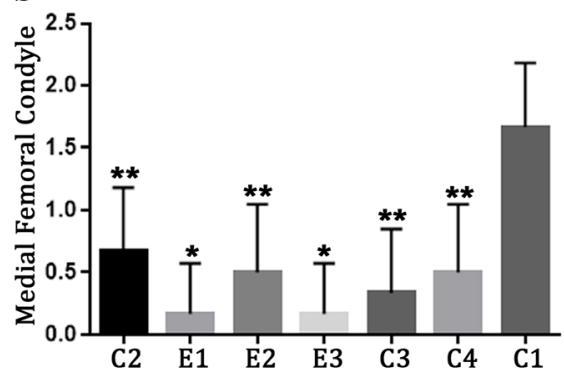

f

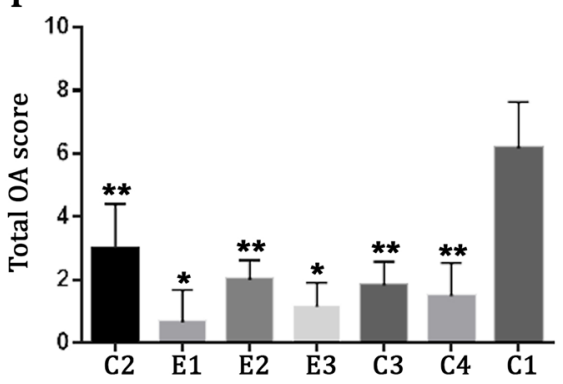

c

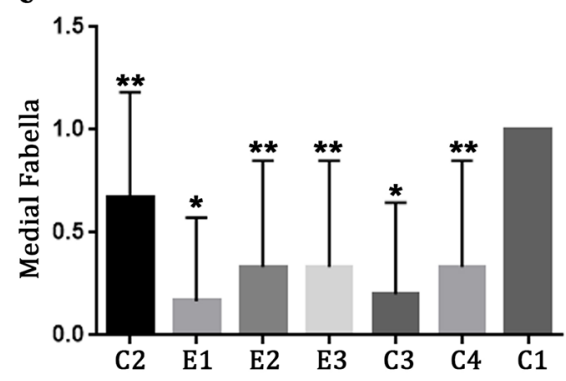

d

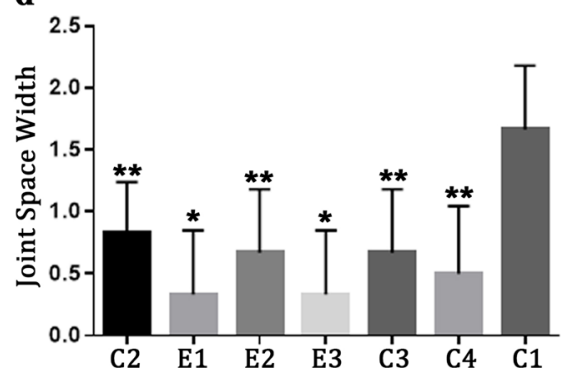

Fig. 1 Radiological evaluations in rat models of OA based on ICRS scoring; data are indicated as mean \pm standard deviation. Groups are named as $\mathrm{C} 1$, receiving no treatment; $\mathrm{C} 2$, receiving $300 \mathrm{mg} /$ day of Piascledine per os (PO) for 10 weeks; C3, $1 \mathrm{mg}$ sodium hyaluronate intra-articularly in days $1,7,14 ;$ C4, 1 mg methyl-prednisolone acetate intra-articularly in days 1, 7, 14; E1, avocado and grape seed oil combination (2:1, $300 \mathrm{mg} /$ day) PO daily; E2, $500 \mathrm{mg} /$ day of grape seed oil PO daily; E3, $200 \mathrm{mg} /$ day grape seed oil intra-articularly in days 1, 7, 14. * $P<0.05$ E1 and E3 versus other treatment groups. ${ }^{* *} P<0.05$ treatment group versus non-treated group (C1)

modulating, and antioxidant activities can have positive effects on OA in terms of prevention or worsening of the symptoms $[19,20]$.

A number of studies that investigated the efficacy of grape seed oil on OA reported promising positive impacts. Woo et al. found that rats receiving grape seed oil had increased foot movement, reduced loss of chondrocytes, reduced inflammatory proteoglycans and cytokines, and reduced osteophyte formation, and concluded that grape seed oil can have protective effects on the devolvement of OA in knee joint in animal models [21]. Hailati et al. reported that procyanidins isolated from grape seed constrains the development of $\mathrm{OA}$ by their anti-oxidative impact, decreasing inflammatory cytokines such as IL-1B, and reducing osteophyte formation. Yet another experiment by Mevel et al. showed that oral administration of 

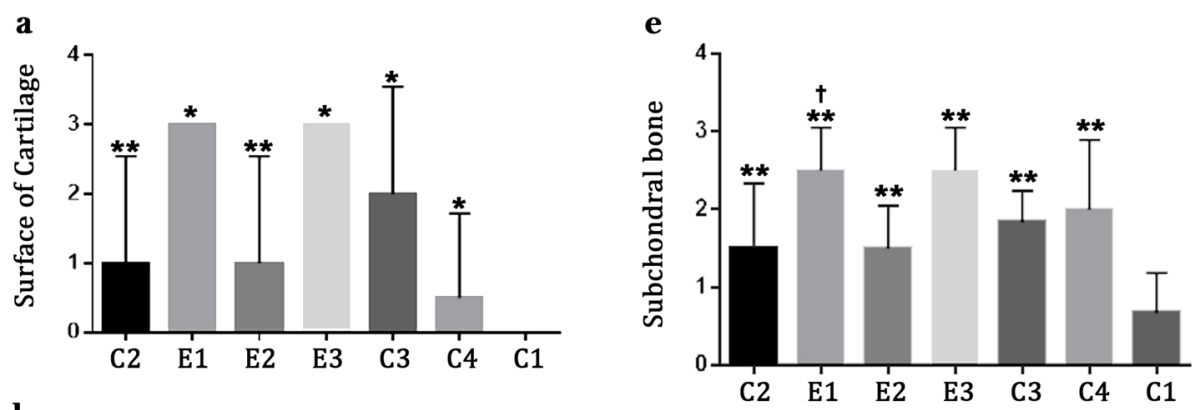

b

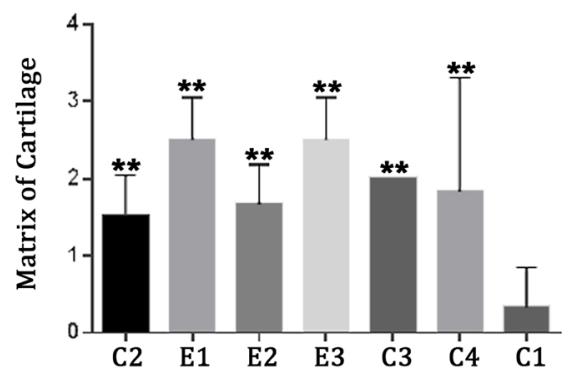

f
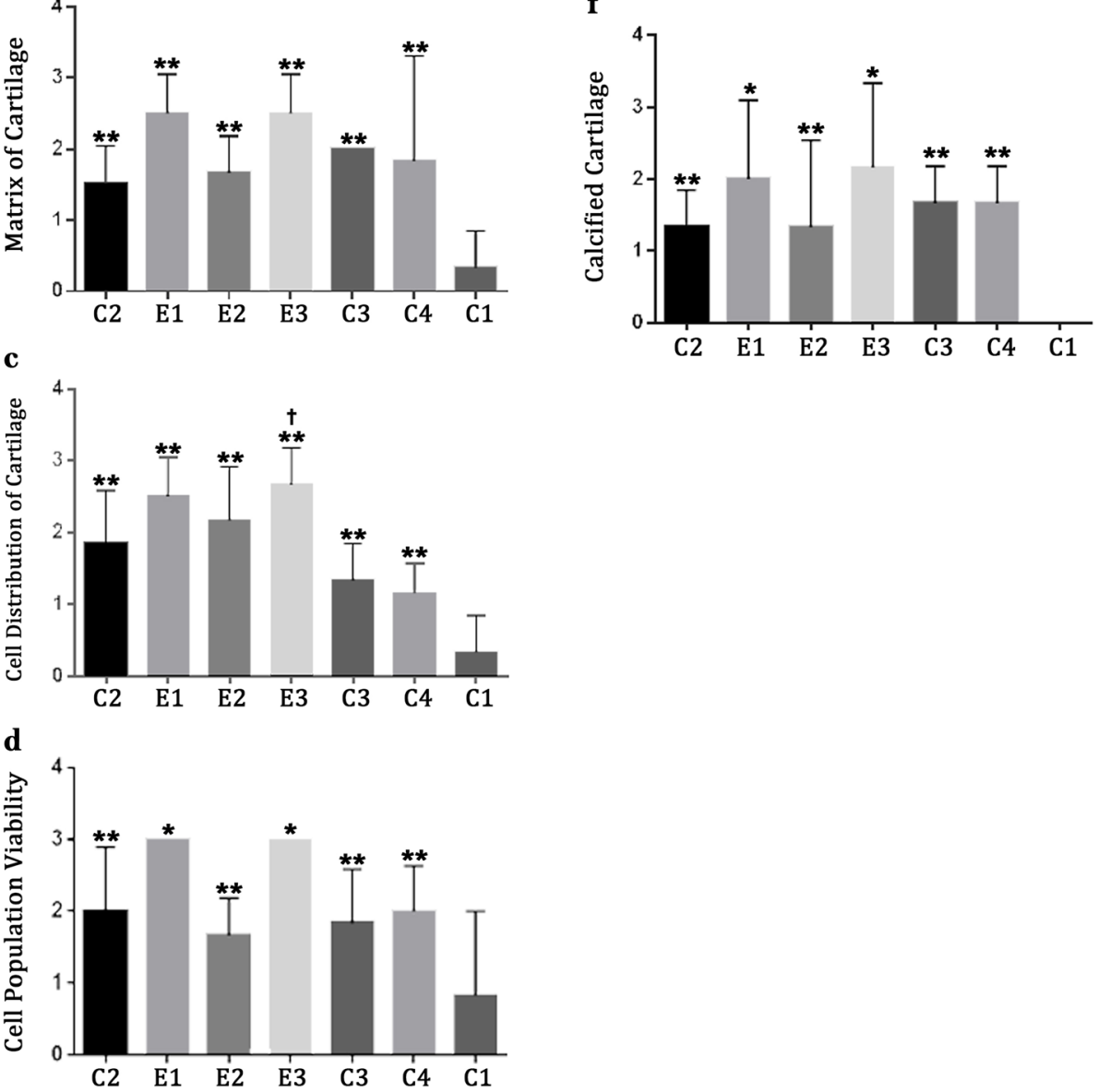

Fig. 2 Pathological findings in rat models of $\mathrm{OA}$; data are presented as mean \pm standard deviation. Groups are named as $\mathrm{C1}$, receiving no treatment; C2, receiving 300 mg/day of Piascledine per os (PO) for 10 weeks; C3, 1 mg sodium hyaluronate intra-articularly in days 1, 7, 14; C4, 1 mg methyl-prednisolone acetate intra-articularly in days 1, 7, 14; E1, avocado and grape seed oil combination (2:1, 300 mg/day) PO daily; E2, 500 $\mathrm{mg} /$ day of grape seed oil PO daily; E3, $200 \mathrm{mg} /$ day grape seed oil intra-articularly in days 1, 7, 14. ${ }^{*} P<0.05 \mathrm{E} 1$ and E3 versus other treatment groups. $+P<0.05 \mathrm{E} 1$ or $\mathrm{E3}$ versus other groups treated via the same route (PO or intra-articular). ${ }^{*} P<0.05$ treatment group versus non-treated group (C1)

olive and grape seed extracts have anti-osteoarthritis effects due to their anti-oxidative and anti-inflammatory effects [19]. Similar results were found in an in vitro study by Jayaprakasha et al. who declared anti-oxidative and anti-inflammatory properties of grape seed oil play the main role regarding its anti-OA effects [22].

Our radiological and pathological studies suggest that intraarticular injection of grape seed oil, as well as oral administration of a combination of grape seed oil and avocado, have promising effects on OA. Its effects on preventing OA were more pronounced compared to routinely used Piascledine-which is a combination of avocado oil and soybean oil, in practice. Yet, intraarticular injection of grape seed oil alone showed better results in contrast with other common injectable medications. Overall, aiming to introduce this medication as an 


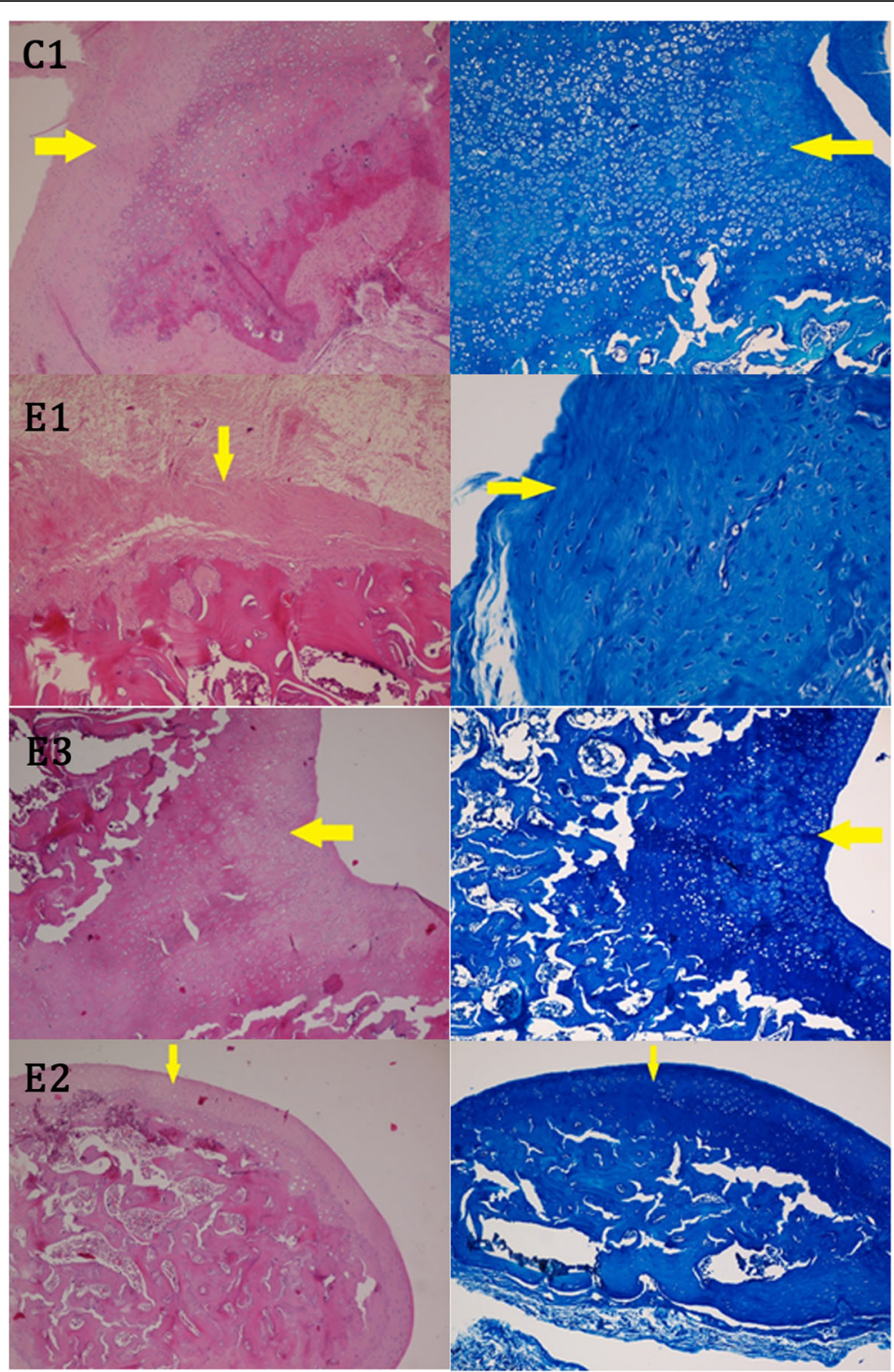

Fig. 3 Samples of tissue sections from articular cartilage in groups C1, E1, E2, E3. Right, toluidine blue; left, hematoxylin and eosin (400x)

alternative treatment for OA, the efficacy of grape seed oil has to be evaluated in clinical studies and possible side effects must be investigated in short- and long-term surveys. However, since grape seed oil is widely used by local populations in many parts of Iran as well as some other countries in the region, proving its beneficial treatment for OA, as a cost-effective remedy in terms of a prevention or symptom reliever, can have a robust effect on the quality of life of these patients.

This study has a few limitations to consider. Though the antioxidative and anti-inflammatory effects of grape seed oil have been evaluated before we did not have the ability to evaluate parameters indicating these effects in our study and further biochemical studies are necessary in this regard. Despite that there are many similarities between knee $\mathrm{OA}$ in rats and its clinical features in humans, one should take note that these experimental models may not reproduce the full complexity of the human disease accurately. Not all factors associated with $\mathrm{OA}$ in humans are fully understood, and physiological biomechanics of the knee differ considerably between rodents and humans. Few in vivo studies have suggested the potential beneficial effects of grape seed oil on human health including cardioprotective, antiinflammatory, antimicrobial, and anticancer properties $[8,12,23]$. However, possible side effects of grape seed oil, and the optimal dosage and application form to prevent disease have not been vastly explored. These 
unanswered questions also emphasize on the need for future in vivo research.

\section{Conclusion}

Using a rat model, we found that grape seed oil, both in its intra-articular injectable form and in its oral administrative form had preventive effects for the development of knee OA. The efficacy of the combination of grape seed oil with avocado was comparable with Piascledine (avocado combination with soybean) which gives us the idea that the constituents of routinely used medications may change. Future in vivo research is required to investigate the potential preventive effects of grape seed oil in humans, as well as the optimal dosage, the application form, and possible side effects.

\section{Abbreviations}

DPPH: 1-diphenyl-2-picrylhydrazyl radical; HLB: Hydrophilic-lipophilic balance; ICRS: International Cartilage Repair Society; IL: Interleukin; OA: Osteoarthritis; PO: Per os

\section{Acknowledgements}

The authors want to thank the Animal House of Shiraz University of Medical Sciences for providing the animals and helping in the induction of the OA model. The authors also appreciate the help of Dr. Sahar Hosseini and the Medipress ${ }^{\mathrm{TM}}$ group for language editing the final proof of the paper.

\section{Authors' contributions}

FS, OKH, Cl, Al, SMS: Experiments and data gathering. NT: Hypothesis and study design. SAE, BL: Data analysis, writing and editing the draft. All of the authors contributed in writing and final revision of the draft. The author(s) read and approved the final manuscript.

\section{Funding}

Not applicable

\section{Availability of data and materials}

The datasets used and/or analyzed during the current study are available from the corresponding author on reasonable request.

\section{Ethics approval and consent to participate}

The study protocol was approved by the Medical Ethics Committee of Shiraz University of Medical Sciences, Shiraz, Iran.

\section{Consent for publication}

Not applicable

\section{Competing interests}

Not applicable.

\footnotetext{
Author details

${ }^{1}$ Stem cells Technology Research Center, Shiraz University of Medical Sciences, Shiraz, Iran. ${ }^{2}$ Department of Pharmacology, School of Medicine, Shiraz University of Medical Sciences, Shiraz, Iran. ${ }^{3}$ Department of Orthopaedic Surgery, Massachusetts General Hospital, Harvard Medical School, Boston, MA, USA. ${ }^{4}$ Foot and Ankle Research and Innovation Laboratory, Massachusetts General Hospital, Harvard Medical School, Boston, MA, USA. ${ }^{5}$ Student Research Committee, Shiraz University of Medical Sciences, Shiraz, Iran. ${ }^{6}$ Central Research Laboratory, Shiraz University of Medical Sciences, Shiraz, Iran. ${ }^{7}$ Department of Medical Biotechnology, School of Advanced Medical Sciences and Technologies, Shiraz University of Medical Sciences, Shiraz, Iran. ${ }^{8}$ Center of Nanotechnology in Drug Delivery, Faculty of Pharmacy, Shiraz University of Medical Sciences, Shiraz, Iran.
}

Received: 16 September 2019 Accepted: 31 August 2020 Published online: 10 September 2020

\section{References}

1. Long MJ, Papi E, Duffell LD, McGregor AH. Predicting knee osteoarthritis risk in injured populations. Clin Biomechanics (Bristol, Avon). 2017;47:87-95.

2. Tanideh N, Nazhvani SD, Bahrami A, Mehrabani D, Akbarzadeh A, Azarpira N, et al. The effect of hydroalcoholic extract of Mangifera indica on induced osteoarthritis of knee in male guinea pigs. 2016;25(5):973-9.

3. Mehranfar S, Abdi Rad I, Mostafavi E, Akbarzadeh AJAC. The use of stromal vascular fraction (SVF), platelet-rich plasma (PRP) and stem cells in the treatment of osteoarthritis: an overview of clinical trials. Nanomed Biotechnol. 2019:47(1):882-90.

4. Chun J, Lee A, Kim J, Choi G, Kim S-HJN. Protective effects of Peucedanum japonicum extract against osteoarthritis in an animal model using a combined systems approach for compound-target prediction. 2018;10(6):754.

5. Wang C, Yan L, Yan B, Zhou L, Sun W, Yu L, et al. Agkistrodon ameliorates pain response and prevents cartilage degradation in monosodium iodoacetate-induced osteoarthritic rats by inhibiting chondrocyte hypertrophy and apoptosis. 2019;231:545-54.

6. Lee YM, Son E, Kim S-H, Kim OS, Kim D-SJPB. Anti-inflammatory and antiosteoarthritis effect of Mollugo pentaphylla extract. 2019;57(1):74-81.

7. Qin R, Sun J, Wu J, Chen LJAJR. Pyrroloquinoline quinone prevents knee osteoarthritis by inhibiting oxidative stress and chondrocyte senescence. 2019:11(3):1460-72.

8. Boileau C, Martel-Pelletier J, Caron J, Msika P, Guillou GB, Baudouin C, et al. Protective effects of total fraction of avocado/soybean unsaponifiables on the structural changes in experimental dog osteoarthritis: inhibition of nitric oxide synthase and matrix metalloproteinase-13. 2009;11(2):R41.

9. Cameron M, Chrubasik S. Oral herbal therapies for treating osteoarthritis. Cochrane Database Syst Rev. 2014;5.

10. Kim S-H, Bang J, Son C-N, Baek W-K, Kim J-MJTKjoim. Grape seed proanthocyanidin extract ameliorates murine autoimmune arthritis through regulation of TLR4/MyD88/NF-kB signaling pathway. 2018;33(3):612.

11. Li W-G, Zhang X-Y, Wu Y-J, Tian XJAPS. Anti-inflammatory effect and mechanism of proanthocyanidins from grape seeds. 2001;22(12):1117-20.

12. Majeed M, Majeed S, Narayanan NK, Nagabhushanam KJPR. A pilot, randomized, double-blind, placebo-controlled trial to assess the safety and efficacy of a novel Boswellia serrata extract in the management of osteoarthritis of the knee; 2019.

13. Koohi-Hosseinabadi O, Ranjbar Z, Sepehrimanesh M, AndisheTadbir A, Poorbaghi SL, Bahranifard H, et al. Biochemical, hematological, and pathological related healing effects of Elaeagnus angustifolia hydroalcoholic extract in 5-fluorouracil-induced oral mucositis in male golden hamster. Environ Sci Pollut Res. 2017;24(31):24447-53.

14. Goebel JC, Bolbos R, Pham M, Galois L, Rengle A, Loeuille D, et al. In vivo high-resolution MRI (7T) of femoro-tibial cartilage changes in the rat anterior cruciate ligament transection model of osteoarthritis: a crosssectional study. Rheumatology. 2010;49(9):1654-64.

15. Boulocher CB, Viguier ER, Cararo RDR, Fau DJ, Arnault F, Collard F, et al. Radiographic assessment of the femorotibial joint of the CCLT rabbit experimental model of osteoarthritis. BMC Med Imaging. 2010:10(1):3.

16. Yanai T, Ishii T, Chang F, Ochiai N. Repair of large full-thickness articular cartilage defects in the rabbit: the effects of joint distraction and autologous bone-marrow-derived mesenchymal cell transplantation. J Bone Jnt Surg Br Vol. 2005;87(5):721-9.

17. Wang AT, Feng $Y$, Jia HH, Zhao M, Yu H. Application of mesenchymal stem cell therapy for the treatment of osteoarthritis of the knee: a concise review. World J Stem Cells. 2019;11(4):222-35.

18. Ravalli S, Szychlinska MA, Leonardi RM, Musumeci GJWJoO. Recently highlighted nutraceuticals for preventive management of osteoarthritis. 2018;9(11):255.

19. Mével E, Merceron C, Vinatier C, Krisa S, Richard T, Masson M, et al. Olive and grape seed extract prevents post-traumatic osteoarthritis damages and exhibits in vitro anti IL-1 $\beta$ activities before and after oral consumption. 2016; 6:33527.

20. Schempp H, Christof S, Mayr U, Treutter D. Phenolic compounds in juices of apple cultivars and their relation to antioxidant activity; 2016. 
21. Woo YJ, Joo YB, Jung YO, Ju JH, La Cho M, Oh HJ, et al. Grape seed proanthocyanidin extract ameliorates monosodium iodoacetate-induced osteoarthritis. 2011;43(10):561.

22. Jayaprakasha G, Selvi T, Sakariah KJFri. Antibacterial and antioxidant activities of grape (Vitis vinifera) seed extracts. 2003;36(2):117-22.

23. Garavaglia J, Markoski MM, Oliveira A, Marcadenti A. Grape seed oil compounds: biological and chemical actions for health. Nutr Metabolic Insights. 2016;9(NMI):S32910.

\section{Publisher's Note}

Springer Nature remains neutral with regard to jurisdictional claims in published maps and institutional affiliations.

Ready to submit your research? Choose BMC and benefit from:

- fast, convenient online submission

- thorough peer review by experienced researchers in your field

- rapid publication on acceptance

- support for research data, including large and complex data types

- gold Open Access which fosters wider collaboration and increased citations

- maximum visibility for your research: over $100 \mathrm{M}$ website views per year

At BMC, research is always in progress.

Learn more biomedcentral.com/submissions 